\title{
ATTITUDES TOWARD COMPLEMENTARY AND ALTERNATIVE MEDICINE, BELIEFS IN AFTERLIFE AND RELIGIOSITY AMONG PSYCHIATRISTS, PSYCHOLOGISTS AND THEOLOGISTS
}

\author{
Žana Kralj $^{1}$ \& Goran Kardum ${ }^{2}$ \\ ${ }^{I}$ Department of Psychiatry, University Hospital Center Split, Split, Croatia \\ ${ }^{2}$ Department of Psychology, Faculty of Humanities and Social Sciences, University of Split, Split, Croatia
}

received: 8.5.2018;

revised: 14.9.2018;

accepted: 5.10.2018

\section{SUMMARY}

Background: The aim of our study was to investigate the differences in beliefs, attitudes toward CAM, beliefs in afterlife and religiosity among the sample of psychiatrists, psychologists, and theologists. Relationship among these constructs could have impact on the concept of mental health.

Subjects and methods: Research was conducted in the Split urban area, Croatia, during 2017 on a sample of psychiatrists $(n=51)$, psychologists $(n=55)$, and theologists $(n=25)$. Participants were presented a figure of the human body, which contained numbers identifying eight different regions of the body. Participants were asked to select which region best represents the location of the self, soul, and mind in the body. We used CAIMAQ (The Complementary, Alternative and Integrative Medicine Attitudes Questionnaire) which contains five subscales. The Afterdeath Beliefs Scale was used to measure the varieties of afterlife beliefs. Analyses showed that applied questionnaires have appropriate reliability and expected factor structure.

Results: The most frequent locations of the Soul were 9 (37\%, Not located in any centralized region in the body) and 5 (31\% chest), whereas Self and Mind were mostly located in the head (43\% and 73\%). Psychiatrists and psychologists have average scores on positive pole of CAIMAQ but did not differ significantly $(p>0.05)$. There were statistical differences between theologists and psychologists/psychiatrists on two subscales: "nutritional counseling and dietary/food supplements can be effective in the treatment of pathology" and "attitudes toward a holistic understanding of the disease" ( $p<0.05)$. There were significant correlations between religion and three CAIMAQ subscales. Although they were mostly religious, psychiatrists and psychologists had a higher average score on Annihilation than theologists. They also did not believe in body resurrection and connection between behavior during life and after death.

Conclusion: The results of our study could have impact on the concept of mental health and in the future must be deeper evaluated within qualitative research methodology.

Key words: alternative medicine - religiosity - afterlife - mental disorders - psychologists - psychiatrists

$* * * * *$

\section{INTRODUCTION}

The holistic model of health care and beliefs suggests that people are composed of physical, psychological, social and spiritual dimensions. The spiritual aspect of life is recognized as an important part of health, wellbeing and quality of life. Throughout history, philosophers, theologians, and scientists have developed various theories about the relationships between the body, self, soul, and mind, which people have adopted, rejected, or revised over time (Anglin 2014).

Clinicians involved in psychiatric care may have noticed that for patients with mental disorders, religion/ spirituality also represents an important way of making sense of and coping with the stress that the illness causes (Huguelet \& Koenig 2009). Religiosity could have significant mental and physical health benefits. There are some differences between belief systems and religious practices. Belief systems as well as religious beliefs are more important than religious practices and behaviors in research on religion and mental health (Flannelly et al. 2006). Inverse relationship was found between belief in life after death and symptom severity on all six symptom clusters that were examined (i.e., anxiety, depression, obsession-compulsion, paranoia, phobia, and somatization) after controlling for demographic and other variables (e.g., stress and social support) that are known to influence mental health. Pleasant afterlife beliefs were associated with better, and unpleasant beliefs were associated with poorer mental health, controlling for age, gender, education, race, income and marital status, social support, prayer and church attendance (Flannelly et al. 2008).

Attitudes according to CAM, certainly belong to the complexity of belief system. The use of complementary and alternative medicine (CAM) is increasing in Europe as well as in the USA, but CAM courses are infrequently integrated into medical curricula (Ditte et al. 2011). Only few chairs or colleges for naturopathy or homeopathy in the US and some single chairs in Europe for hydrotherapy or naturopathy can be regarded as an exception to the rule in the $19^{\text {th }}$ and $20^{\text {th }}$ century, whereas traditional medicine remained in the cultures as a kind of folk medicine often provided by lay physicians and sometimes also by physicians with their institutions and inventions (Melzer et al. 2013). People use comple- 
mentary medicine because they are attracted to it rather than because they are disillusioned with orthodox medicine. Both treatment and illness beliefs have an important role in explaining why people use complementary medicine (Bishop et al. 2006). Intuitive thinking, paranormal beliefs and ontological confusions predicted $34 \%$ of the variation in CAM beliefs, whereas the other variables increased the prediction only by $4 \%$ (Lindeman 2011).

The complexity of the belief system of experts in the field of mental health and their implicit model of mental health is certainly one of the factors influencing the diagnosis and treatment of mental illnesses. There is evidence that religious backgrounds and beliefs, as well as the importance attributed to religion, may differ between health professionals (particularly academicians) and adults in the general community. Results of this and other studies may indicate a gap in religious orientation between health care providers and patients and that such a gap could hinder the recognition of and proper care for spiritual needs in the hospital setting (Koenig et al. 1991). There is also a difference between experts in the field of mental health and the academic community.

Fifty percent of professors of psychology at US universities and colleges do not believe in any god, and another $11 \%$ are agnostic. That makes them the least religious of a all mental health professionals (Gross \& Simmons 2009). More than any other helping profession, psychologists' beliefs have tended to differ from the general public's beliefs. Psychologists surveyed were found to be the least religious of mental health professionals studied: clinical psychologists, clinical social workers, marriage and family therapists, and psychiatrists (Bergin 1980, Sullivan 1998). Results indicated significant differences across the five professions with regards to their religious affiliation, frequently used religious and spirituality practices and activities, degree to which each profession self-identifies as spiritual, as well as intrinsic religiosity (Oxhandler et al. 2017).

Research indicates that therapists are open to religious/spiritual issues, that clients want to discuss these matters in therapy, and that the use of religious/spiritual interventions for some clients can be an effective adjunct to traditional therapy interventions (Post \& Wade 2009).

The best data available is provided by surveys carried out by mental health professionals. Examining religious beliefs in a random sample of 555 psychologists from the American Psychological Association (APA), Ragan and colleagues found that $43 \%$ believed in God, $27 \%$ attended church twice a month or more often and only $9 \%$ held leadership positions in their congregations. The overall level of religiosity among psychologists was much lower than that of the general population and academicians in general (Ragan et al. 1980, Shafranske \& Malony 1990). Has the disparity in religiosity between clinicians and the general public decreased in recent years? Clinician members of the American Psychological Association (APA) were surveyed regarding their religion and spirituality. Although no less religious than A. E. Bergin and J. P. Jensen's (1990) sample, psychologists remained far less religious than the clients they serve with more psychologists selecting Jewish - and were more than twice as likely to select no religious affiliation. (Delaney et al. 2007). Physicists were much more likely to perceive church membership as important than were psychologists. Psychologists were less religiously committed than physicists because psychologists were more likely to study religion as an aspect of human behavior (Lehman \& Witty 1931). Psychologists deny the mysterious element in natural phenomena more than physicists and also psychologists believe that their science could explain most phenomena. Lehman also coined the term "scholarly distance from religion" and it positively correlated with personal religiosity (Lehman \& Shriver 1968). Few psychologists endorsed coexisting religious and scientific belief systems (Eckhardt et al. 1992). Psychologists reported mild to moderate involvement and identification with religion, which is much lower than that found among the general public.

Education in medicine also appears to be a significant variable in the research of attitudes and beliefs. In general students responded more positively to the principles of CAIM than to CAIM treatment and the higher quality of CAIM-related medical education would facilitate appropriate integration of CAIM into medical curricula (Abbott et al. 2011). Psychiatrists continue to be less religious than nonpsychiatrist physicians. Historic tensions between psychiatry and religion may continue to shape the interaction between the two realms (Curlin et al. 2007). The problems that patients also have is a significant variable. Pediatric oncologists more than pediatricians see religion and spirituality as relevant to their professional work especially when families are making medical decisions and in end of life situations. Physicians tend to view religion and spirituality functionally, describing impermeable boundaries in medical decision making situations and more permeable boundaries at the end of life (Sikand \& Laken 1998). The encounter with death is a very sensitive event and is strongly associated with the belief system. Core variations in postmortem beliefs can be described in terms of the fate of consciousness (awareness), identity (memory, personality), and physicality (the body) beyond the death event (Burris \& Bailey 2009).

We investigate the differences in beliefs, attitudes toward complementary and alternative medicine, beliefs in after death and religiosity among sample of psychiatrists, psychologists, and theologists. Relationships among these constructs could have impact on the concept of mental health and also on diagnosis and treatment of mental disorders. 


\section{SUBJECTS AND METHODS}

\section{Subjects}

Participans were psychiatrist $(\mathrm{n}=51)$, psychologist $(\mathrm{n}=55)$, and thologists $(\mathrm{n}=25)$ who lived and work in Split-Dalmatian county. Most of them are professional staff from Clinic for psychiatry University Hospital Center Split and the others work in both inpatient and outpatient, public and private health clinic. The period of data collection was from November to December 2017.

Table 1 describes the sample $(n=132)$ that consists of psychologist $(n=51)$, psychiatrists $(n=56)$ and theologists $(n=25)$. Out of 56 psychiatrists, $30(59 \%)$ were female and $21(41 \%)$ were male whereas out of 51 psychologist, $49(89 \%)$ were female and $6(11 \%)$ were male. The sample of theologists $(n=25)$ were all male and $52 \%$ of them are ages between 56 and $65,7(28 \%)$ from $36-45,4(16 \%)$ from 26 to 35 , and one (4\%) from 46 to 55 . The most of psychiatrists $(66 \%)$ were from 36 and $45(31 \%)$ and also between 46 and $55(35 \%)$ years old. More than one-third (36\%) psychologist were between 26 and 35 years old and also between 46 and $55(33 \%)$.

\section{Instruments}

Participants were presented a figure of the human body, which contained numbers identifying eight different regions of the body (Anglin 2014). Participants were asked to select which region best represents the location of the self, soul, and mind in the body.

To examine attitudes towards alternative and complementary medicine we used CAIMAQ questionnaire (The Complementary, Alternative and Integrative Medicine Attitudes Questionnaire) which contains of five subscales (Abbott et al. 2011). The Complementary, Alternative and Integrative Medicine Attitudes Ques- tionnaire (CAIMAQ) was developed by a panel of experts in the field of complementary, alternative and integrative medicine. The CAM categories used by the National Center for Complementary and Alternative Medicine (NCCAM) were used to measure attitudes toward specific CAM modalities (NCCIH 2018). NCCAM classifies CAM therapies into five categories: whole medical systems (e.g., homeopathic medicine, naturopathic medicine, traditional Chinese medicine, ayurveda), mind-body medicine (e.g., meditation, prayer, art, music, dance), biologically based practices (e.g., dietary supplements, herbal products), manipulative and body-based practices (e.g., chiropractic manipulation, massage) and energy medicine (including both biofield therapies (e.g., Tai Chi, Qi Gong, Reiki, Therapeutic Touch) and bioelectromagnetic-based therapies (e.g., the medical use of pulsed fields, magnetic fields, alternating-current, direct-current fields). The CAIMAQ included 30 items where each item conducted on seven-point Likert scale, ranging from one (strongly disagree) to seven (strongly agree).

The Afterdeath Beliefs Scale (ADBS scale) was used to measure five varieties of afterlife beliefs: Annihilation, Disembodied Spirit, Spiritual Embodiment, Reincarnation, and Bodily Resurrection (Burris \& Bailey 2009). Five varieties of afterlife beliefs organize according to secular thought and tradition of East and West. Reincarnation and Disembodied Spirit are most commonly associated with Eastern traditions, Bodily Resurrection and Spiritual Embodiment are more closely allied with Western traditions, and Annihilation is most typical of modern, secular thought. ADBS qustionnaire consists of 24 items where each item conducted on seven-point Likert scale, ranging from one (strongly disagree) to seven (strongly agree).

Analysis show that applied questionnaire have an appropriate reliability and factor structure of theoreticaly proposed structure of questionnaire.

Table 1. Demographic and professional background characteristics of psychologists $(n=51)$, psychiatrists $(n=56)$ and theologists $(\mathrm{n}=25)$

\begin{tabular}{lccc}
\hline & Psychologist & Psychiatrists & Theologists \\
Demographic background variable & N $(\%)$ & N $(\%)$ & - \\
\hline Age & & & $1(2)$ \\
To 25 & $2(3.6)$ & $8(16)$ & $7(16)$ \\
$26-35$ & $20(36)$ & $16(31)$ & $1(4)$ \\
$36-45$ & $13(24)$ & $18(35)$ & $13(52)$ \\
$46-55$ & $18(33)$ & $8(16)$ & - \\
$56-65$ & $2(3.6)$ & $30(59)$ & $25(100)$ \\
Sex & & $21(41)$ & - \\
Female & $49(89)$ & & - \\
Male & $6(11)$ & 0 & $25(100)$ \\
Religious belief & $10(18)$ & $2(4)$ & - \\
Atheist & $4(7)$ & $47(92)$ & - \\
Agnostic & $39(71)$ & 0 & \\
Catholic & $1(2)$ & $2(4)$ & \\
Christian & $1(2)$ & & \\
Other & & & \\
\hline
\end{tabular}




\section{Procedure}

After the Ethical approval from University Hospital Centre Split, 160 questionnaire was distibuted to the group of psychiatrist and psychologist from the Clinic for psychiatry as well as to theologists. Before the questionnaire was applied to the group an information about the research was provided and after that the questionnaries were given to the recipients who agreed to participate. Each of participants got an individual envelope with the questionnaire. Envelope contained instructions about the study and it was not necessary in the questionnaire to leave any personal information that might reaveal the identity of participants. On the first page were directions which they read before completing. Using snowball method these participants shared questionnaire to their colleague -coworkers, members of Croatian Psychiatrist Association and Croatian Psychological Association. Recipients were asked to return questionnaire by post within month.

\section{Statistical analysis}

We used $\mathrm{R}$ software to analysis the data ( $\mathrm{R}$ Core Team 2018). Descriptive statistics and some (Revelle 2018) preparation function for analysis were done with the psych package for psychological research. We used chi square test and mosaic plot for analysis the differences betwee groups according to location of self, mind and soul. In order to determine the differences among group in CAIMQ and ADBS dimensions with analysis of variance were done with car (Fox \& Weisberg 2011) and afex (Singmann et al. 2018) packages. Post-hoc tests were conducted with Tukey HSD approach that help us identify a significant difference among groups. Figures were done with the functions within the yarrr package (Phillips 2017). We used 95\% cut off $(p<0.05)$ for significance of various tests.

\section{RESULTS}

There were statistical difference $\left(\chi^{2}=8.63, \mathrm{p}=0.003\right)$ in religious belief between psychiatrists and psychologist because of higher rate of atheist (18\%) and lower number of Catholics (71\%) in psychologist group then in psychiatrists $(0 \%$ atheist, $92 \%$ Caholics $)$. We also asked the respondents on a scale from 1 to 7 about the importance of faith in everyday life. There were statistically significant difference $(F=17.6, p<0.001)$ in the importance of faith in everyday life. Theologists have average value of 7 . Theologists have statistically significant $(p<0.001)$ higher average value according to psychologists and psychiatrists. Psychologists have an average of 4.3 while psychiatrists a value of 4.9 and they are not statistically significant $(p=0.106)$ in the importance of religion to everyday life.

We asked the respondents where are the self, mind and soul on the image of the body (Figure 1,2). The most frequent location of the Soul were answer $9(37 \%$,
Not located in any centralised region in the body) and 5 ( $31 \%$, chest). There were not statistical difference $\left(\chi^{2}=3.25, \mathrm{df}=2, \mathrm{p}=0.196\right)$ between psychologists (19, $35 \%)$, psychiatrists $(16,31.4 \%)$ and theologists (13, $52 \%$ ) in the belief that souls is not located in any centralised region in the body.

The most frequent location of the Self were answer 2 $(43 \%$, the head) and $9(45 \%$, Not located in any centralised region in the body). There were statistical difference $\left(\chi^{2}=6.1, \mathrm{df}=2, \mathrm{p}=0.047\right)$ between psychologists $(24,44 \%)$, psychiatrists $(25,49 \%)$ and theologists $(7$, $28 \%$ ) in the belief that self is located in the head. Theologians at least believe that self is placed in the head.

The most of respondents believe that mind is located in the head $(95,73 \%)$. There were not statistical difference $\left(\chi^{2}=1.3, \mathrm{df}=2, \mathrm{p}=0.519\right)$ between psychologists $(40,73 \%)$, psychiatrists $(39,76 \%)$ and theologists $(16$, $64 \%$ ) in the belief that mind is located in the head.



Figure 1. Where is soul, mind and self? 

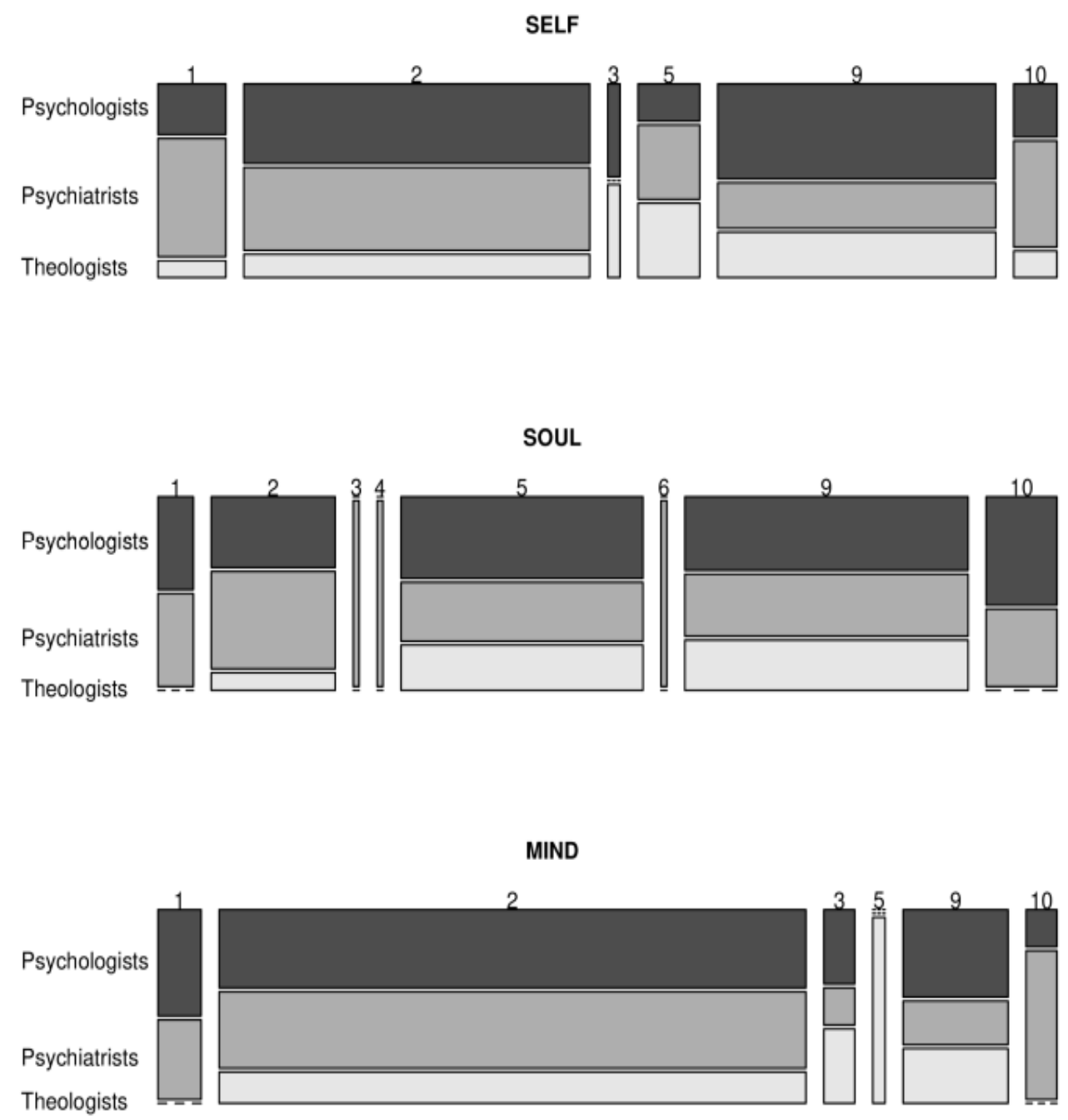

Figure 2. Where is soul, mind and self - among psychiatrists, psychologists and theologists (1-8, 9- not located in any centralized region in the body, 10 - does not exist)

The CAIMAQ questionnaire analysis shows differences between respondents on certain dimensions (Figure 3). There were statistical difference $(\mathrm{F}=3.48, \mathrm{df}=2$, $\mathrm{p}=0.036$ ) between groups on Desirability of CAIM Therapies dimension. Psychiatrists have statistically significantly $(\mathrm{p}=0.03)$ lower average values than psychologists. There were not statistical significant $(\mathrm{F}=3.14$, $\mathrm{p}=0.05$ ) differences on the dimension Progressive $\mathrm{Pa}$ tient/Physician Health Care Roles. Theologists have statistically significant higher average score then psychologists $(p<0.001)$ and psychiatrists $(p=0.011)$ on dimension Mind body spirit connection. On the dimension of Principles of Allostasis there were not statistical significant difference $(\mathrm{F}=1.1, \mathrm{p}=0.335)$ between group. Finally, theologists have statistically significant higher average score then psychologists $(\mathrm{p}<0.001)$ and psychiatrists $(\mathrm{p}=0.001)$ on dimension Holistic Understanding of Disease.

Analysis of the results of applying ADBS questionnaire shows the difference between psychologists, psychiatrists and theologians on six subscales (Figure 4). On the Bodily Resurrection subscale there were statisticaly significant difference $(\mathrm{F}=72.3, \mathrm{p}<0.001)$ in average values between psychologists, psychiatrists and theologists. Tukey multiple comparisons of means show that theologians have a statistically significantly higher $(\mathrm{p}<0.001)$ average value than psychologists and psychiatrists. There weren't significant $(p=0.904)$ difference between psychologists and psychiatrists. The same significance $(\mathrm{F}=29.28, \quad \mathrm{p}<0.001)$ difference between psychologists, psychiatrists and theologists is on the Annihilation scale where theologists have significance $(p<0.001)$ lowest average value according to psychologists and psychiatrists. There weren't significant $(p=0.663)$ difference between psychologists and psychiatrists. On the Spiritual Embodiment scale there is also statistical significant difference $(\mathrm{F}=10.2, \mathrm{p}<0.001)$ among groups where theologists have the significant $(p<0.01)$ highest average score comparing to psychologists and psychiatrists. There weren't significant $(\mathrm{p}=0.517)$ difference between psychologists and psychiatrists. On the Disembodied Spirit scale there is also a significant difference $(\mathrm{F}=5.12, \mathrm{p}<0.001)$ between groups where theologians have the statistically significant lowest $(\mathrm{p}<0.05)$ mean value compared to psychologists and psychiatrists. On the Belief Efficacy scale there is 



Figure 3. CAIMAQ dimensions among psychiatrists, psychologists, and theologists
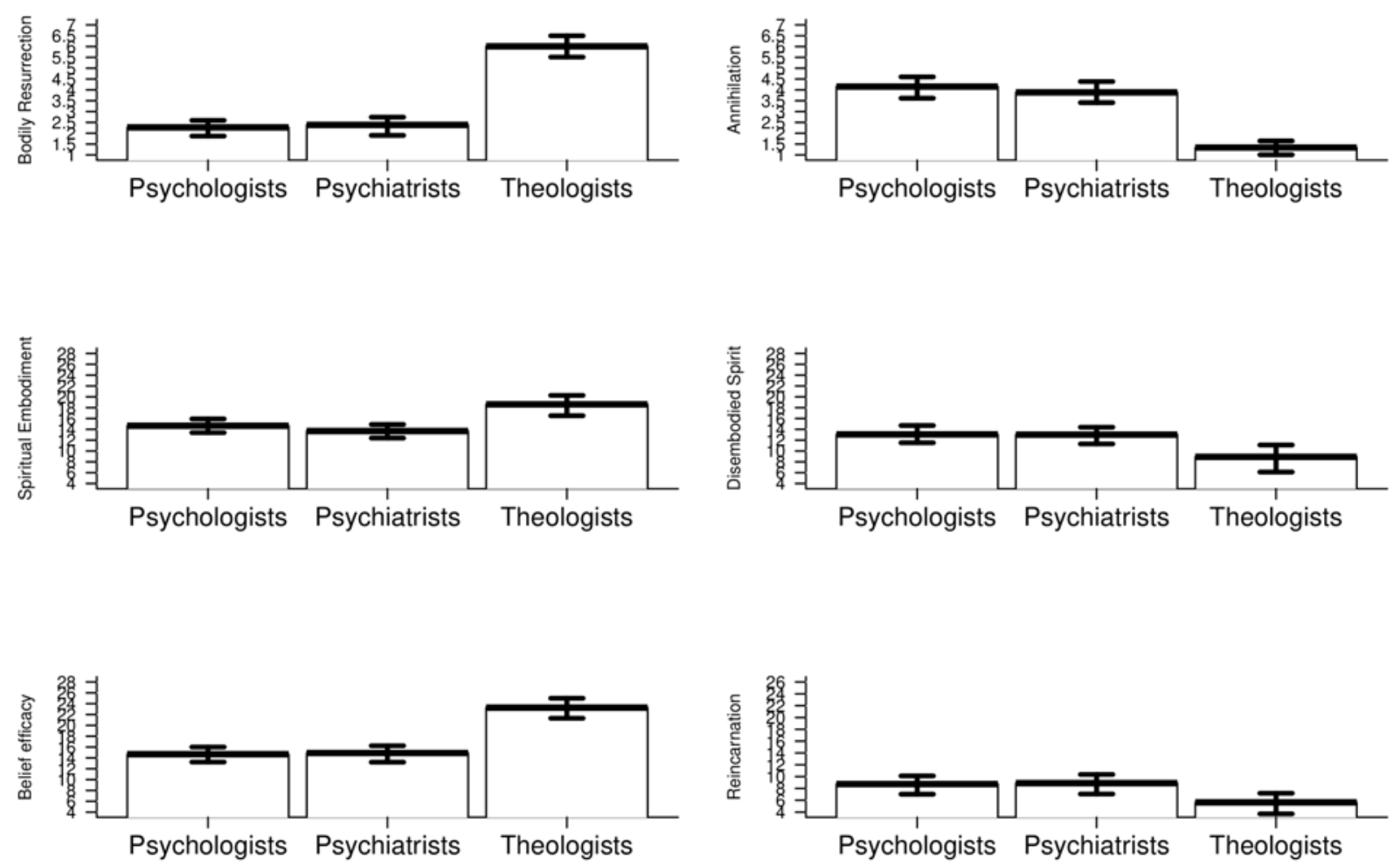

Figure 4. After death believe scale dimensions among psychiatrists, psychologists, and theologists 
also a significant difference $(\mathrm{F}=28.1, \mathrm{p}<0.01)$ but unlike previous scale, theologians have a statistically significantly higher average value compared to psychiatrists and psychologists $(\mathrm{p}<0.001)$. Psychologists and psychiatrists do not differ $(p=0.97)$ in the average values. Finally, on the Reincarnation scale $(\mathrm{F}=3.81, \mathrm{p}=0.025)$, theologians have the smallest average value which is significantly different $(\mathrm{p}<0.05)$ from psychiatrists and psychologists. Psychologists and psychiatrists do not differ $(p=0.986)$ in the average values.

\section{DISCUSSION}

In this research we investigates the differences in beliefs, attitudes toward CAM, beliefs in after death and religiosity among sample of psychiatrists, psychologists, and theologists.

The results show some differences between psychologists, psychiatrists and theologians in relation to religion, attitudes towards complementary and alternative medicine, and belief in after death. Psychiatrists and psychologists compared to theologians have lower average values regarding the importance of faith in everyday life. Among the psychologists is the largest number of those who declare themselves as atheists.

Participants were presented a figure of the human body which contained numbers identifying eight different regions of the body and participants were asked to select which region best represents the location of the self, soul, and mind. This issue is important because it has certain implications for the concept of mental health. The most common answer to the question where is the soul was that can not be located in any region of the body. This is thought by more than $30 \%$ of psychologists and psychiatrists and just over $50 \%$ of the theologists. The second most common answer for the location of the soul is the chest and that is the answer for $30 \%$ of the respondents. The self and the mind are most located in the head, i.e. asnwer for the self more than $40 \%$ while for the mind about $70 \%$.

These results are quite different from the study of Anglin (2014) on the students of psychology from USA university where the most common response for the location of the soul is the chest while the mind is located in the head (more than $90 \%$ of the examinees) and the self also in the chest (27\%). Our findings point out the possible importance of the education, culture and religion of respondents. However, there is a difference between two samples, employed adults in the field of mental health and students.

There are differences between groups of respondents regarding attitudes towards complementary and alternative medicine. The holistic approach and emphasis on the importance of the connection between soul and body are largely advocated by theologians and are significantly different from psychiatrists and psychologists. This is could be understand because of the differences in education. This results can also be associated with previous analyzes of the location of the soul, self and mind. In the same way, the results of the questionnaire of belief after death are related to the beliefs and attitudes towards complementary and alternative medicine.

Psychologists and psychiatrists on the two dimensions relating to the religions of the East have significantly higher results than the theologians. Conversely, theologians have significantly higher results than psychiatrists and psychologists on two dimensions of Western, Christian religiosity. Psychologists and psychiatrists do not believe in the Christian dimensions of resurrection and state of mind after death. They have significantly lower results on the dimensions of the Bodily Resurrection and Spiritual Embodiment. Finally, the biggest differences are on the Anninhalation dimension, which is a reflection of contemporary, secular thoughts and contemporary changes in society. Although they are religious, psychiatrists and psychologists have higher average score on Annihilation than theologists. They also do not beleive in body resurrection and connection between behavior during life and after death. Psychologists and psychiatrists considerably believe that there is nothing after death. These results are in line with a studies (Delaney et al. 2007, Gross \& Simmons 2009, Oxhandler et al. 2017, Sullivan 1998) that show the deviation of mental health professionals from the general population. The results can be related to education, knowledge, and faith in a wider context. The results are in line with Lehman \& Shriver (1968) who says that psychologists deny the mysterious element in natural phenomena and believe that their science could explain most phenomena.

This research has a number of limitations such as a sample in selected Croatian urban area. It should do research in the wider area with random selection of mental health professionals. There must be also using different methodology such as interview and discussion groups. That could be helpful because of complexity of research phenomena. In the future, these results should be compared with the sample of patients and general population.

\section{CONCLUSION}

Studies indicate that religion and spirituality can promote mental health through positive religious coping, community and support, and positive beliefs. In this context, education of mental health professionals should improve the various forms of education and increased awareness of religion and spirituality. The results of our study could have impact on concept of mental health and in the future must be deeper evaluate within qualitative research methodology with different sample of patients and general population as well as mental health professionals.

\section{Acknowledgements: None.}

Conflict of interest: None to declare. 


\section{Contribution of individual authors:}

Žana Kralj: study design, data collection, literature search, manuscript writing, approval of the final version;

Goran Kardum: study design, data collection, literature search, statistical analysis, manuscript writing, approval of the final version.

\section{References}

1. Abbott RB, Hui K-K, Hays RD, Mandel J, Goldstein M, Winegarden B, et al.: Medical Student Attitudes toward Complementary, Alternative and Integrative Medicine. Evidence-Based Complementary and Alternative Medicine 2011. doi:10.1093/ecam/nep195

2. Anglin SM: I think, therefore I am? Examining conceptions of the self, soul, and mind. Consciousness and Cognition 2014; 29:105-16. doi:10.1016/j.concog.2014.08.014

3. Bergin AE: Psychotherapy and Religious Values. Journal of Consulting and Clinical Psychology 1980:95-105

4. Bishop FL, Yardley L, Lewith GT: Why do people use different forms of complementary medicine? Multivariate associations between treatment and illness beliefs and complementary medicine use. Psychology \& Health 2006; 21:683-98 doi:10.1080/14768320500444216.

5. Burris CT, Bailey K: What Lies Beyond: Theory and Measurement of Afterdeath Beliefs. The International Journal for the Psychology of Religion 2009; 19:173-86. doi:10.1080/10508610902879982

6. Curlin FA, Odell SV, Lawrence RE, Chin MH, Lantos JD, Meador KG, et al.: The Relationship Between Psychiatry and Religion Among U.S. Physicians. Psychiatr Serv 2007; 58:1193-8. doi:10.1176/appi.ps.58.9.1193

7. Delaney HD, Miller WR, Bisonó AM: Religiosity and spirituality among psychologists: A survey of clinician members of the American Psychological Association. Professional Psychology: Research and Practice 2007; 38:538-46

8. Ditte D, Schulz W, Ernst G, Schmid-Ott G: Attitudes towards complementary and alternative medicine among medical and psychology students. Psychology, Health \& Medicine 2011; 16:225-37.

doi:10.1080/13548506.2010.532559

9. Eckhardt CI, Kassinove H, Edwards L: Religious Beliefs and Scientific Ideology in Psychologists: Conflicting or Coexisting Systems? Psychol Rep 1992; 71:131-45. doi:10.2466/pro.1992.71.1.131

10. Flannelly KJ, Ellison CG, Galek K, Koenig HG: Beliefs about life-after-death, psychiatric symptomology and cognitive theories of psychopathology. Journal of Psychology and Theology 2008; 36:94-103

11. Flannelly KJ, Koenig HG, Ellison CG, Galek K, Krause $N$ : Belief in life after death and mental health: findings from a national survey. J Nerv Ment Dis 2006; 194:524-9. doi:10.1097/01.nmd.0000224876.63035.23
12. Fox J, Weisberg S: An R Companion to Applied Regression. second. Thousand Oaks, CA, USA: Sage Publications; 2011

13. Gross N, Simmons S: The Religiosity of American College and University Professors. Sociology of Religion 2009; 70:101-29. doi:10.1093/socrel/srp026

14. Huguelet P, Koenig HG: Religion and Spirituality in Psychiatry. 1st ed. Cambridge University Press; 2009

15. Koenig HG, Bearon LB, Hover M, Travis JL: Religious perspectives of doctors, nurses, patients, and families. $J$ Pastoral Care 1991; 45:254-67

16. Lehman EC, Shriver DW: Academic Discipline As Predictive of Faculty Religiosity. Social Forces 1968; 47:17182. doi:10.2307/2575147

17. Lehman HC, Witty PA: Certain Attitudes of Present-Day Physicists and Psychologists. The American Journal of Psychology 1931; 43:664-78. doi:10.2307/1415179

18. Lindeman M: Biases in intuitive reasoning and belief in complementary and alternative medicine. Psychology \& Health 2011; 26:371-82. doi:10.1080/08870440903440707

19. Melzer J, Deter H-C, Uehleke B: CAM in Psychiatry. Evid Based Complement Alternat Med 2013; 2013. doi:10.1155/2013/293248

20. NCCIH: National Center for Complementary and Integrative Health. NCCIH 2018. https://nccih.nih.gov/ (accessed April 26, 2018)

21. Oxhandler HK, Polson EC, Moffatt KM, Achenbaum WA: The Religious and Spiritual Beliefs and Practices among Practitioners across Five Helping Professions. Religions 2017; 8:237. doi:10.3390/rel8110237

22. Phillips Nyarrr: A Companion to the e-Book "YaRrr!: The Pirate's Guide to R." 2017

23. Post BC, Wade NG: Religion and spirituality in psychotherapy: a practice friendly review of research. Journal of Clinical Psychology 2009; 65:131-46. doi:10.1002/jclp.20563

24. $R$ Core Team R: A Language and Environment for Statistical Computing. Vienna, Austria: R Foundation for Statistical Computing; 2018

25. Ragan C, Newton Malony H, Beit-Hallahmi B: Psychologists and religion: professional factors and personal belief. Review of Religious Research 1980; 21:208-17

26. Revelle W:psych: Procedures for Psychological, Psychometric, and Personality Research. Evanston, Illinois: Northwestern University; 2018

27. Shafranske EP, Malony HN:Clinical psychologists' religious and spiritual orientations and their practice of psychotherapy. Psychoth of Psychotherapists' Spirituality on Their Practice. University Press of America; 1998erapy: Theory, Research, Practice, Training 1990; 27:72-8. doi:10.1037/0033-3204.27.1.72

28. Sikand A, Laken M: Pediatricians' experience with and attitudes toward complementary/alternative medicine. Arch Pediatr Adolesc Med 1998; 152:1059-64

29. Singmann H, Bolker B, Westfall J, Aust F: Analysis of Factorial Experiments, 2018

30. Sullivan JP: On Holy Ground: The Impact of Psychotherapists' Spirituality on Their Practice. University Press of America; 1998

\section{Correspondence:}

Ass. Professor Goran Kardum, PhD

Department of Psychology, Faculty of Humanities and Social Sciences, University of Split

Poljicka 35, 21000 Split, Croatia

E-mail: gkardum@ffst.hr 